\title{
Dopaminergic Neurons Encode a Distributed, Asymmetric Representation of Temperature in Drosophila
}

\author{
Seth M. Tomchik \\ Department of Neuroscience, The Scripps Research Institute Florida, Jupiter, Florida 33458
}

\begin{abstract}
Dopaminergic circuits modulate a wide variety of innate and learned behaviors in animals, including olfactory associative learning, arousal, and temperature-preference behavior. It is not known whether distinct or overlapping sets of dopaminergic neurons modulate these behaviors. Here, I have functionally characterized the dopaminergic circuits innervating the Drosophila mushroom body with in vivo calcium imaging and conditional silencing of genetically defined subsets of neurons. Distinct subsets of PPL1 dopaminergic neurons innervating the vertical lobes of the mushroom body responded to decreases in temperature, but not increases, with rapidly adapting bursts of activity. PAM neurons innervating the horizontal lobes did not respond to temperature shifts. Ablation of the antennae and maxillary palps reduced, but did not eliminate, the responses. Genetic silencing of dopaminergic neurons innervating the vertical mushroom body lobes substantially reduced behavioral cold avoidance, but silencing smaller subsets of these neurons had no effect. These data demonstrate that overlapping dopaminergic circuits encode a broadly distributed, asymmetric representation of temperature that overlays regions implicated previously in learning, memory, and forgetting. Thus, diverse behaviors engage overlapping sets of dopaminergic neurons that encode multimodal stimuli and innervate a single anatomical target, the mushroom body.
\end{abstract}

\section{Introduction}

Dopaminergic neurons are involved in modulating a variety of behaviors in animals, including learning (Wise, 2004; Davis, 2011), arousal (Andretic et al., 2005), motor control (Hauber, 1998), motivation (Wise, 2004), addiction and obesity (Kenny, 2011; Lüscher and Malenka, 2011), and salience-based decisionmaking (Zhang et al., 2007; Doya, 2008). The complexity of behavioral roles of dopamine is likely attributable, at least in part, to the anatomical complexity of dopaminergic circuits. In mammals, numerous dopaminergic neurons originate in the substantia nigra and ventral tegmental area. Single-cell recordings have revealed heterogeneity of dopaminergic neuron responses to rewarding and aversive stimuli, and it appears that they comprise multiple circuits with distinct roles in motivational control (Bromberg-Martin et al., 2010). In Drosophila, dopaminergic neurons innervate the mushroom body (among other regions) (Mao and Davis, 2009), in which they modulate aversive learning (Schwaerzel et al., 2003; Claridge-Chang et al., 2009; Aso et al., 2010; Davis, 2011), forgetting (Berry et al., 2012; Plaçais et al., 2012), state-dependent modulation of appetitive memory re-

Received Aug. 17, 2012; revised Nov. 28, 2012; accepted Dec. 7, 2012.

Author contributions: S.M.T. designed research; S.M.T. performed research; S.M.T. contributed unpublished reagents/analytic tools; S.M.T. analyzed data; S.M.T. wrote the paper.

This work was supported by National Institutes of Health/National Institute of Mental Health Grant K99 MH092294. I thank Ronald L. Davis for providing laboratory space, major equipment, and mentoring support. Ronald Davis and Germain Busto provided helpful feedback on this manuscript. Jacob Berry wrote a MATLAB script to calculate the normalized responses from GCaMP and RFP traces. Vivek Jayaraman, Kei Ito, Brian Howell, Josh Dubnau, Scott Waddell, Hiromu Tanimoto, and Jacob Berry generously provided fly stocks.

The author declares no competing financial interests.

Correspondence should be addressed to Dr. Seth M. Tomchik, Department of Neuroscience, The Scripps Research Institute Florida, 130 Scripps Way, \#3C1, Jupiter, FL 33458. E-mail: stomchik@scripps.edu.

DOI:10.1523/JNEUROSCI.3933-12.2013

Copyright $\odot 2013$ the authors $\quad 0270-6474 / 13 / 322166-11 \$ 15.00 / 0$ trieval (Krashes et al., 2009), expression of ethanol-induced reward memory (Kaun et al., 2011), arousal (Andretic et al., 2005; Lebestky et al., 2009), and temperature-preference behavior (Bang et al., 2011).

The role of dopamine in learned behaviors, particularly olfactory aversive learning, is well established. Synaptic output of dopaminergic neurons, as well as expression of dopamine receptors on mushroom body neurons (the putative postsynaptic targets), is necessary for aversive olfactory associative learning (Schwaerzel et al., 2003; Kim et al., 2007). Furthermore, dopaminergic neurons respond to negative reinforcers (Riemensperger et al., 2005; Mao and Davis, 2009), and stimulation of dopaminergic neurons in lieu of negative reinforcement leads to the formation of aversive memory in both larvae and adult flies (Schroll et al., 2006; Claridge-Chang et al., 2009; Aso et al., 2010, 2012). Dopamine functions in concert with neuronal activity in the mushroom bodies to synergistically elevate cAMP (Tomchik and Davis, 2009) and protein kinase A (Gervasi et al., 2010), providing a mechanism through which mushroom bodies integrate information about sensory stimuli and dopaminergic circuit activity.

To understand the role of dopaminergic circuits in behavior, it is critical to understand what information dopaminergic circuits encode and how it is transmitted across the multiple parallel circuits that drive behavior. How dopaminergic neurons encode stimuli related to innate versus learned behaviors and how this information is segregated (or integrated) across dopaminergic circuits are open questions. Here, I have physiologically characterized the responses of dopaminergic neurons to changes in temperature with in vivo functional imaging and examined the behavioral effects of conditional silencing of subsets of these neurons. I focused on dopaminergic neurons innervating the 
mushroom body, which have been implicated in both olfactory learning (Waddell, 2010) and temperature-preference behavior (Bang et al., 2011). The results demonstrate that dopaminergic neurons encode an asymmetric representation of temperature that is broadly distributed across the PPL1 dopaminergic neurons innervating distinct spatial regions of the mushroom body. Thus, multimodal sensory information is integrated across multiple parallel channels with potentially redundant behavioral function.

\section{Materials and Methods}

Fly maintenance and GAL4 drivers. Flies were cultured on standard cornmeal/agar medium with $12 \mathrm{~h}$ light/dark cycles at $25^{\circ} \mathrm{C}$ unless otherwise indicated. Various galactosidase-4 (GAL4) lines were used to drive expression of GAL4 in subsets of dopaminergic neurons, using a mushroom-body-specific GAL80 repressor (MBGAL80) to remove GAL4 expression in the mushroom body when necessary. The driver lines were as follows: tyrosine hydroxylase (TH)-GAL4 (Friggi-Grelin et al., 2003), w;MBGAL80;C150 (Dubnau et al., 2003), w;MBGAL80; MZ840 (Tanaka et al., 2008), NP7198;MBGAL80 (Tanaka et al., 2008), NP7135;MBGAL80 (Tanaka et al., 2008), C061;MBGAL80 (www.flytrap.org; Krashes et al., 2009), MZ604 (Ito et al., 1998; Tanaka et al., 2008), NP2755/CyO (Tanaka et al., 2008), and NP5272 (Tanaka et al., 2008). The MBGAL80 stock was constructed by Hiromu Tanimoto (Max Planck Institut für Neurobiologie, Martinsried, Germany) and characterized by Krashes et al. (2007).

In vivo imaging. Flies bearing a TH-GAL4 or Dopa decarboxylase (Ddc)-GAL4 transgene were crossed with w;UAS-GCaMP3,UAS-red fluorescent protein (RFP) flies. Progeny of either sex were collected $<10$ $\mathrm{d}$ after eclosion for imaging. Each fly was mounted in a fly holder designed to allow saline to flow over the dorsal head (including the antennae), thorax, and abdomen. The holder was custom fabricated by a machine shop from polycarbonate, and a recording chamber (Warner Instruments) was mounted on top. Myristic acid was used to hold the fly's body and head in place. A small window was cut in the cuticle above the fly brain to allow optical access, and the recording chamber was filled with saline containing the following (in $\mathrm{mm}$ ): $103 \mathrm{NaCl}, 3 \mathrm{KCl}, 5 \mathrm{HEPES}$, $1.5 \mathrm{CaCl}_{2}, 4 \mathrm{MgCl}_{2}, 26 \mathrm{NaHCO}_{3}, \mathrm{NaH}_{2} \mathrm{PO}_{4}, 10$ trehalose, 7 sucrose, and 10 glucose (Tomchik and Davis, 2009). The saline was perfused at 2 $\mathrm{ml} / \mathrm{min}$ throughout the imaging. The temperature of the saline was modulated with an inline heater/cooler (Warner Instruments), monitored with a thermistor placed $2 \mathrm{~mm}$ lateral and $1 \mathrm{~mm}$ anterior to the fly's head, and recorded via an analog-to-digital converter and associated software (Axon Digidata 1440A; Molecular Devices). Activity of dopaminergic neurons was monitored with a confocal microscope (Leica TCS SP5). Images were collected at $2 \mathrm{~Hz}$ with $5 \times$ line averaging. One photomultiplier tube was used to detect GCaMP fluorescence $(510-550 \mathrm{~nm})$, and another was used to detect RFP fluorescence $(610-700 \mathrm{~nm})$. Imaging periods were $5 \mathrm{~min}$ for brief temperature shifts or $8 \mathrm{~min}$ for sustained cooling. Regions of interest were drawn around neuropil or somata of dopaminergic neurons innervating the mushroom body (Fig. $1 B-D$; see Fig. $6 B, E, F)$, and the mean fluorescence intensity was calculated. Dopaminergic neurons innervating the $\alpha$ and $\alpha^{\prime}$ lobes were imaged simultaneously in the same plane of section (Fig. $1 B$ ), as were the MV1 and MP1 neurons (Fig. 1D); V1 neurons were imaged separately (Fig. 1C). Basal temperature was maintained at $25^{\circ} \mathrm{C}$ during the experiments except when otherwise indicated. Each brain region was imaged up to three times per fly, recording the responses to $(1)$ brief heating $\left(32^{\circ} \mathrm{C}\right),(2)$ brief cooling $\left(18^{\circ} \mathrm{C}\right)$, and $(3)$ sustained cooling $\left(18^{\circ} \mathrm{C}\right.$ for $>2 \mathrm{~min}$, with a total ramp-hold time of $3 \mathrm{~min}$ ). The starting stimulus for each animal was alternated between the brief heating and cooling. When all three stimuli were presented, the sustained cooling was presented last to avoid any potential desensitization. A separate set of animals was recorded presenting only this stimulus to ensure that its presentation order did not affect the experiment results, i.e., there was no significant difference in the response amplitudes between brains when the cooling stimulus was presented first versus last (see Fig. 4C). Imaging data were analyzed essentially as in the study by Berry et al. (2012). Briefly, normalized GCaMP and RFP signals were calculated by fitting the minima of $5 \mathrm{~s}$ bins of time series data to a line. To correct for motion, the ratio of the normalized GCaMP/RFP signals was calculated to yield normalized, motioncorrected time series data in units of $\% \Delta F / F$, and a three-point moving average was applied.

Response magnitudes were calculated as the average $\% \Delta F / F$ values across the $5 \mathrm{~s}$ time period centered on the highest value within a given time window (all time windows were $25 \mathrm{~s}$ in duration). The following time windows were used for brief cooling/heating: pre (37.5-62.5 s), peak [cooling] (87.5-112.5 s), peak [heat] (75-100 s), and post (162.5-187.5). The pre window was selected as the last 25-s stretch before the chamber temperature was shifted. The peak window was centered on the peak of the temperature shift as recorded in the chamber (the heating element was slightly faster than the cooling, reflected in the earlier peak time). The post window was the first $25 \mathrm{~s}$ window in which the temperature had returned to a stable baseline. For sustained cooling experiments, the following time windows were used: pre (37.5-62.5 s), peak (87.5-112.5 s), hold (167.5-192.5 s), and post (347.5-372.5 s). In experiments in which some groups had no response to the stimulus [e.g., when applying tetrodotoxin (TTX); see Fig. 5B], I calculated the mean response across the entire $25 \mathrm{~s}$ time window. Heat maps were generated in MATLAB (MathWorks). To determine whether a cell or neuropil region exhibited robust responses to a stimulus, the peak $\Delta F / F$ response for each soma was calculated, and the pre $\Delta F / F$ was subtracted to account for any ongoing activity. Responses $\geq 10 \% \Delta F / F$ were considered to be robust, positive responses. For all imaging experiments, $n \geq 10$ flies.

Temperature-preference behavior assay. Flies of the genotype w; tubulinGAL80ts;UAS-Kir2.1 were crossed to various GAL4 lines. The flies were reared at $18^{\circ} \mathrm{C}$ in a temperature, humidity, and light cyclecontrolled incubator (Conviron) and then either kept at $18^{\circ} \mathrm{C}$ (uninduced) or moved to $30^{\circ} \mathrm{C}$ (induced) for $4 \mathrm{~d}$ before testing ( $3 \mathrm{~d}$ for C150-GAL4 flies). Flies of both sexes were tested immediately after removal from the incubator. All flies were age matched and $<10 \mathrm{~d}$ after eclosion; comparisons were made between paired groups of induced and uninduced flies that were run simultaneously. Temperature preference was assayed essentially as described previously (Sayeed and Benzer, 1996). An aluminum plate $(65 \times 10.16 \mathrm{~cm})$ was placed with one end on top of a hotplate and the other on a cold plate. Two fly run areas, $32 \times$ $4.5 \times 0.2 \mathrm{~cm}$ each, were fabricated from expanded polyvinyl chloride and centered on top of the aluminum plate. The temperature gradient was monitored with nine thermocouples (Pico Technologies), mounted every $4 \mathrm{~cm}$ on the bottom of the aluminum plate underneath the fly run area. A polycarbonate sheet was placed over the top of the apparatus and coated with Rain-X (Illinois Toolworks) to prevent flies from evading the temperature gradient (Hamada et al., 2008). A linear temperature gradient was set up, spanning $\sim 14-38^{\circ} \mathrm{C}$ in the run area. The slope of a line fit to the temperatures measured across the nine thermocouples was $0.757^{\circ} \mathrm{C} / \mathrm{cm}$. Groups of 30 flies each were lightly anesthetized with $\mathrm{CO}_{2}$, with the exposure adjusted so that the flies were immobilized just long enough to place them in the run areas and close the lid before they resumed walking. The flies were allowed to distribute along the gradient for $30 \mathrm{~min}$ and then photographed with a digital camera. Temperature at each thermocouple was recorded once per minute with a data logger and associated software (Pico Technologies). Fly positions across the gradient were analyzed in Illustrator (Adobe Systems) by counting the number of flies in each of 16 bins in an overlaid grid (every other bin boundary was on a thermocouple). Avoidance indices (Hong et al., 2008) against low temperatures $\left(\mathrm{AI}_{\text {low }}\right)$ and high temperatures $\left(\mathrm{AI}_{\text {high }}\right)$ were calculated according to the following equations:

$$
\begin{aligned}
\mathrm{AI}_{\text {low }} & =\frac{N_{\text {int }}-N_{\text {low }}}{N_{\text {int }}+N_{\text {low }}}, \\
\mathrm{AI}_{\text {high }} & =\frac{N_{\text {int }}-N_{\text {high }}}{N_{\text {int }}+N_{\text {high }}},
\end{aligned}
$$

where $N_{\text {low }}$ is the number of flies in the region below $22.2^{\circ} \mathrm{C}, N_{\text {int }}$ is the number of flies in the region between 22.2 and $26.7^{\circ} \mathrm{C}$, and $N_{\text {high }}$ 


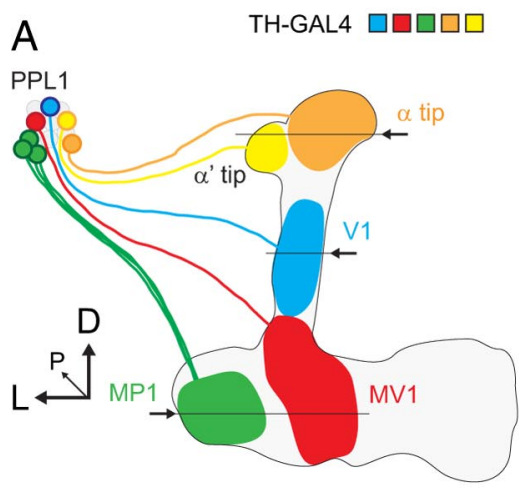

$E$
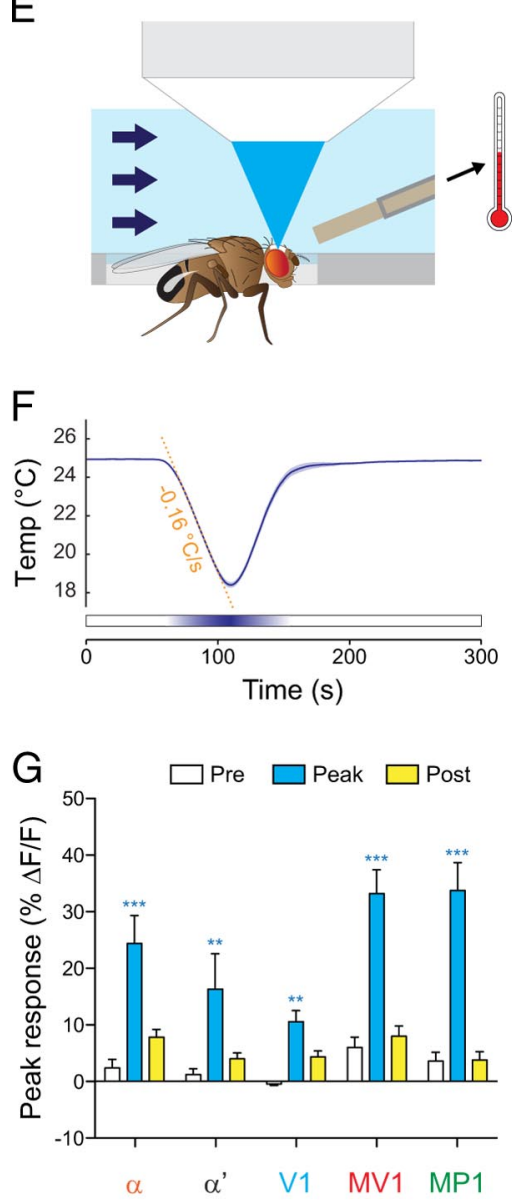
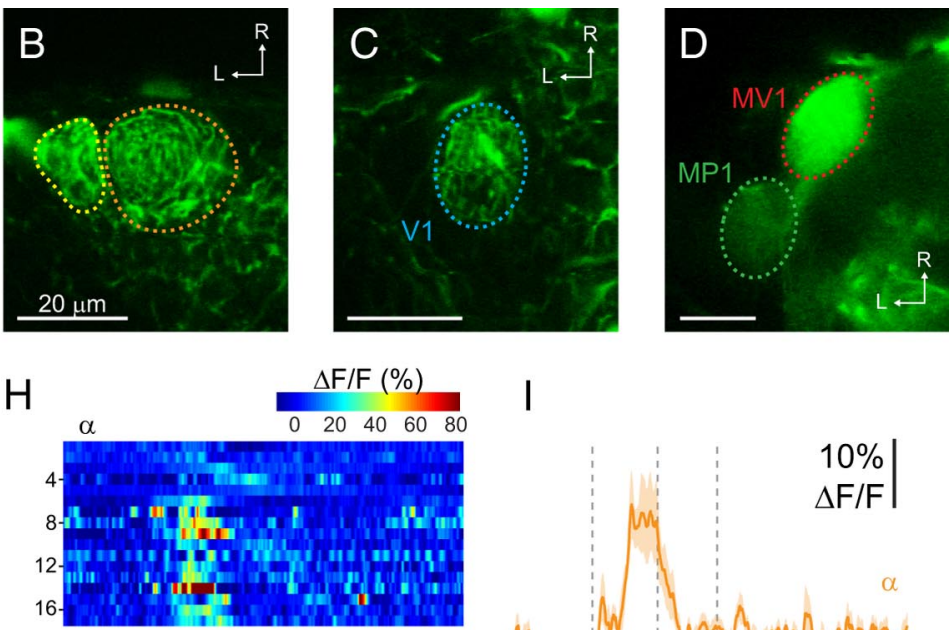

$\alpha$
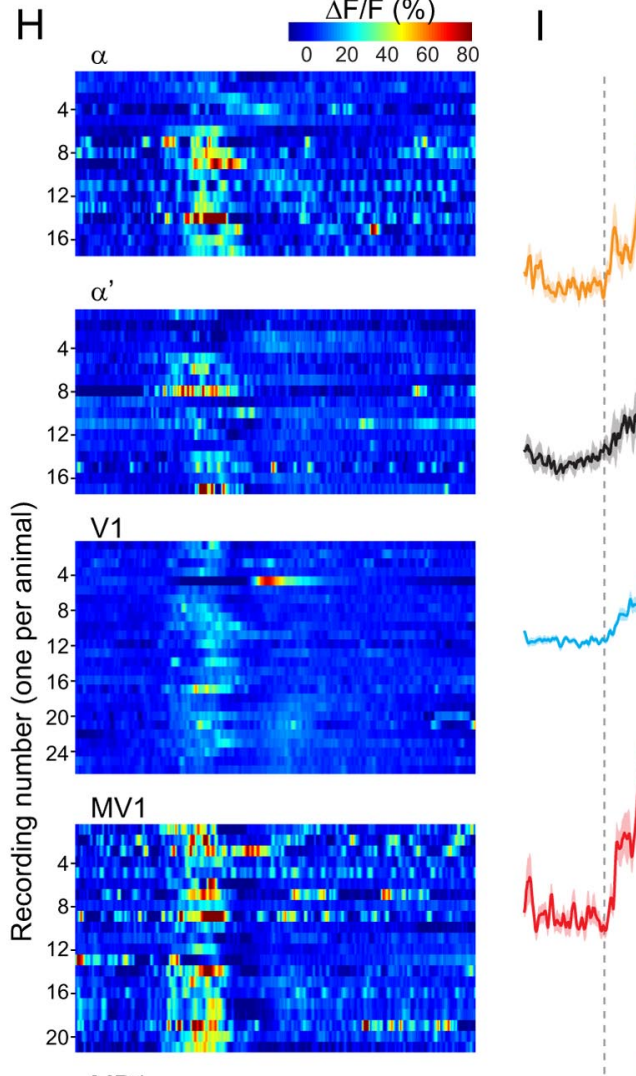

$10 \%$

$\Delta \mathrm{F} / \mathrm{F}$
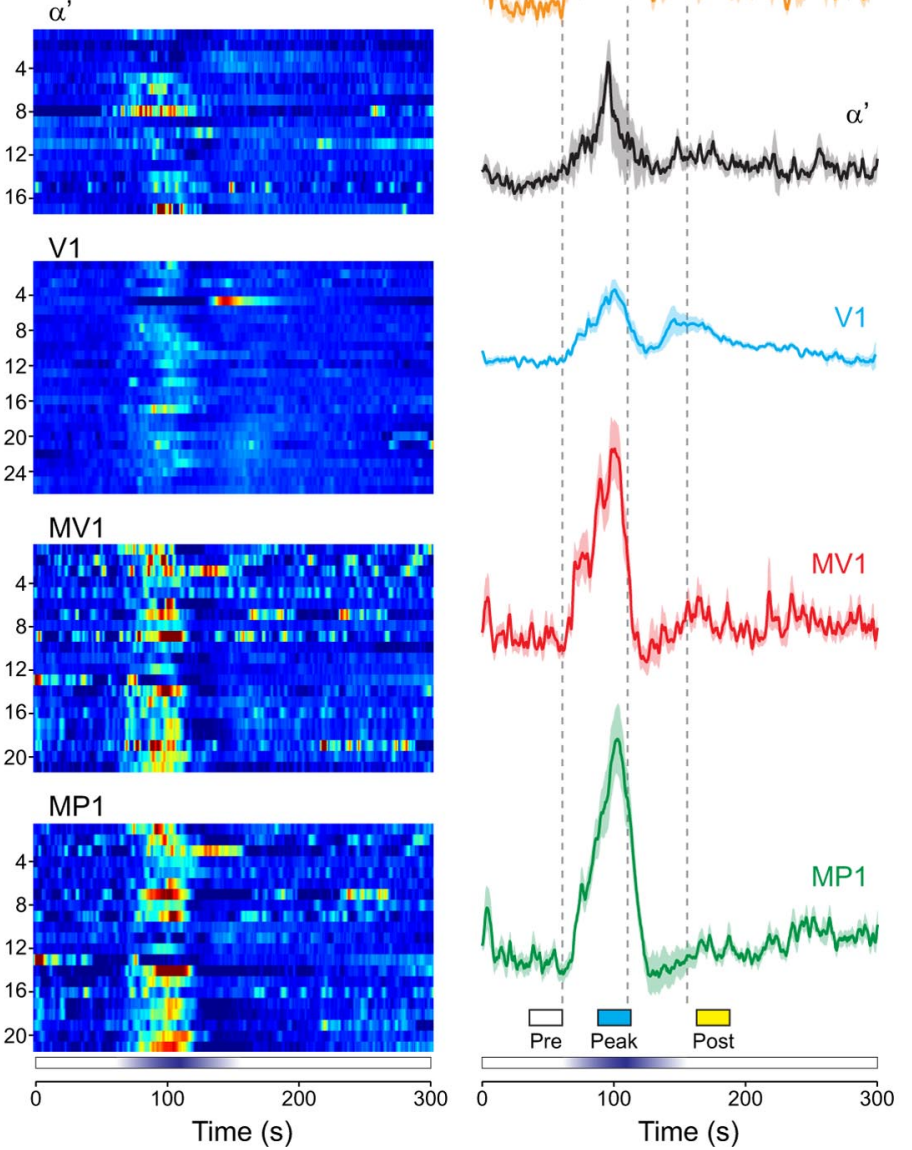

Figure 1. Imaging setup and responses of dopaminergic neurons to brief cooling. $\boldsymbol{A}$, Illustration of the dopaminergic neurons from the PPL1 cluster that innervate the mushroom body vertical lobes. The mushroom body lobes are outlined, and each subset of dopaminergic neurons is illustrated in a different color. Arrows and horizontal lines indicate the planes of optical sections for the imaging experiments. D, Dorsal; L, lateral; P, posterior; R, rostral. $\boldsymbol{B}-\boldsymbol{D}$, Confocal images of TH-GAL4>UAS-GCaMP expressed in the $\alpha / \alpha^{\prime}$ tips, V1 neuron, and MV1/MP1 neurons, respectively. $\boldsymbol{E}$, Illustration of the imaging setup, showing the fly mounted in the recording chamber, the flow of the saline solution (arrows), the thermistor used to monitor temperature next to the fly's head, and the objective of the confocal microscope (not to scale). $\boldsymbol{F}$, Temperature recorded next to the fly's sead during brief cooling experiments. Mean (dark blue line) \pm SEM (light blue surround) are graphed ( $n=57$ ). The orange dashed line fit to the cooling phase shows the rate of the temperature change $\left(-0.16^{\circ} \mathrm{C} / \mathrm{s}\right) . \mathbf{G}$, Peak response magnitudes during three time windows (Pre, Peak, and Post; see bottom of $I$ ) across each subset of dopaminergic neurons. ${ }^{* *} p<0.01$, ${ }^{* * *} p<0.001$ (Bonferroni's test). $\boldsymbol{H}$, Heat maps of the responses of individual dopaminergic neurons (1 imaged per fly) to cooling. I, Responses of each subset of dopaminergic neurons to cooling. Mean (dark lines) \pm SEM (light surrounds) are shown. Vertical dashed gray lines show the beginning, peak, and end of the temperature shift.

is the number of flies in the region above $26.7^{\circ} \mathrm{C}$. For each genotype, $n \geq 8$.

Statistical analyses. Data were processed with custom MATLAB (MathWorks) scripts. Statistical analyses were performed in Prism (GraphPad Software). Omnibus ANOVAs followed by Bonferroni's multiple comparison tests were used to make comparisons across groups when the $\Delta F / F$ values did not significantly differ from normality
(D’Agostino and Pearson's test); Kruskal-Wallis tests followed by Dunn's post hoc analyses were used otherwise.

\section{Results}

To investigate the role of dopaminergic neurons in encoding stimuli associated with an innate behavior (temperature- 
preference behavior), the effect of changes in temperature on dopaminergic activity was measured with calcium imaging in vivo. I expressed a genetically encoded calcium indicator, GCaMP3 (Tian et al., 2009), under control of the GAL4/UAS system (Brand and Perrimon, 1993). An RFP (Pramatarova et al., 2006) was coexpressed and used to normalize the GCaMP response and compensate for any small motions in the preparation. Expression of GCaMP was initially targeted to dopaminergic neurons innervating the vertical lobes of the mushroom body using TH-GAL4 driver (Friggi-Grelin et al., 2003). This drives expression in multiple sets of dopaminergic neurons innervating distinct spatial regions of the mushroom body, such as V1 (innervating the vertical lobe stalk), MP1 (heel), and MV1 (lower stalk/junction), and dopaminergic neurons innervating the tips of the mushroom body $\alpha$ and $\alpha^{\prime}$ lobes (henceforth referred to simply as $\alpha$ and $\alpha^{\prime}$ ) (Fig. 1A-D) (Tanaka et al., 2008). Dopaminergic neurons were imaged in vivo through a window in the cuticle. Temperature of the saline bathing the brain and dorsal aspect of the head (including the antennae), thorax, and abdomen was maintained at $25^{\circ} \mathrm{C}$ and ramped up or down to examine the effect of temperature shifts on the dopaminergic neurons (Fig. $1 A-E$ ).

Cooling the fly from 25 to $18^{\circ} \mathrm{C}$ (at a rate of $-0.16^{\circ} \mathrm{C} / \mathrm{s}$ ) generated increases in calcium activity across multiple dopaminergic neurons (Fig. $1 F-I$ ). Peak response magnitudes were significantly larger than the baseline values in all areas: $\alpha, \alpha^{\prime}, \mathrm{V} 1, \mathrm{MV} 1$, and MP1 [two-way ANOVA: $F_{(4,2)}=51.86, p<0.001$; Bonferroni's test: $t_{(2)}=5.41(\alpha), 3.71\left(\alpha^{\prime}\right), 3.35(\mathrm{~V} 1), 7.41(\mathrm{MV} 1)$, and 8.21 (MP1), $p<0.01$ ]. Similar to previous studies (Berry et al., 2012; Plaçais et al., 2012), ongoing activity in MP1 and MV1 was observed before any explicit experimental manipulation; this was also observed in the $\alpha$ tip (Fig. 1H; see Fig. 3B). Thus, the coolinginduced increase in calcium responses was observed across both dopaminergic neurons that exhibited ongoing calcium activity $\left(\alpha\right.$, MV1, MP1) and ones that did not ( $\left.\alpha^{\prime}, \mathrm{V} 1\right)$ (Fig. 1I). The dopaminergic neurons were highly sensitive to the shift in temperature; calcium transients reached a threshold response value (defined as the mean baseline response $+3 \mathrm{SDs}$ ) when the temperature had dropped by $2.5 \pm 0.2^{\circ} \mathrm{C}$ (Fig. 2). There was no significant difference in the threshold temperature across the different dopaminergic neurons (Kruskal-Wallis test: $H=2.44, p=$ 0.66). The responses peaked before the trough of the cooling when analyzed across all neurons (two-way ANOVA: $F_{(4,1)}=$ $7.09, p<0.01$ ); post hoc analysis revealed that the MV1 neuron in particular exhibited responses that peaked significantly sooner than the peak temperature shift (Bonferroni's test: $t_{(4)}=3.02$, $p<0.05$ ) (Fig. 2C). This suggested that the neurons may adapt to the stimulus, a possibility explored further below.

To determine whether dopaminergic neurons respond symmetrically to temperature shifts (i.e., to temperature increases as well as decreases), I ramped the temperature from 25 to $32^{\circ} \mathrm{C}$. Remarkably, there were no consistent responses to heating in any of the imaged regions (Fig. $3 B-D$ ). A response to heating was observed in only one fly in $\alpha, \alpha^{\prime}$, and V1 (Fig. 3B), and it occurred during the falling phase when the temperature was decreasing from the peak (rather than increasing toward it). Ramping the temperature further, up to $37^{\circ} \mathrm{C}$, likewise produced no activity in dopaminergic neurons. Thus, dopaminergic neurons encode changes in temperature asymmetrically, responding specifically to cooling (Fig. 3D).

Responses of dopaminergic neurons to cooling could reflect a monotonic response to temperature, in which ongoing (tonic) dopaminergic activity is inversely proportional to temperature.
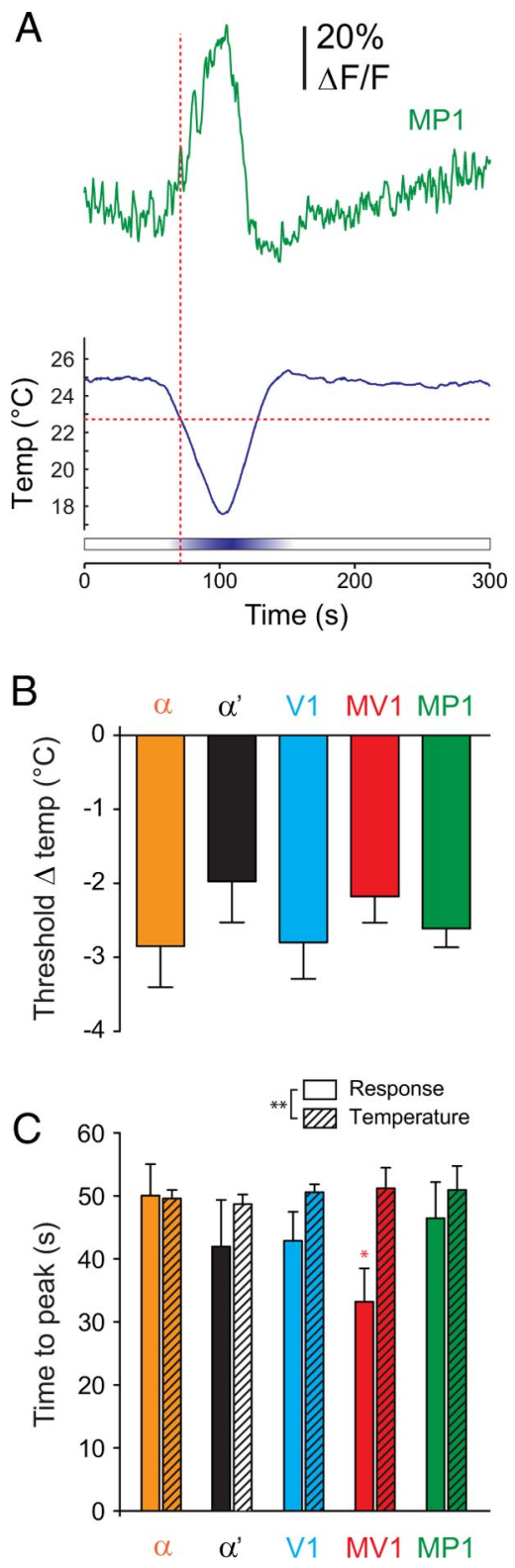

Figure 2. Temporal dynamics of dopaminergic neuron responses to cooling. $A$, Example of a GCaMP calcium trace recorded from MP1 during cooling, along with the temperature trace from the same recording. This neuron reached a defined response threshold (mean +3 SDs) at $22.7^{\circ} \mathrm{C}\left(\Delta\right.$ temp $\left.=2.3^{\circ} \mathrm{C}\right)$, marked by the intersection of the red dashed lines. $\boldsymbol{B}$, Threshold temperature ( $\Delta$ temp; mean \pm SEM) calculated for each subset of dopaminergic neurons. $C$, Time from the onset of cooling to the peak change in temperature (temperature minimum) and the peak dopaminergic neuron response. ${ }^{*} p<0.05$ (Bonferroni's test), ${ }^{* *} p<0.01$ (two-way ANOVA). The MV1 neurons peaked while the temperature was still falling.

Alternatively, the neurons could respond specifically to the change in temperature (phasic activity) or combination of the two (phasic-tonic activity). To distinguish among these possibilities, I conducted an experiment in which the temperature was ramped down and held at $18^{\circ} \mathrm{C}$ before returning to $25^{\circ} \mathrm{C}$. The total ramp-hold time was $3 \mathrm{~min}$, with the temperature in the recording chamber measuring $\leq 19^{\circ} \mathrm{C}$ for $136.9 \pm 13.3 \mathrm{~s}$ ( mean \pm SD) (Fig. 4A). Dopaminergic neurons exhibited increases in activity as the temperature ramped down toward $18^{\circ} \mathrm{C}$ (Fig. $4 B-D$ ). These responses quickly adapted to a lower steady-state level as the temperature was held at $18^{\circ} \mathrm{C}$. The onset peak was significantly higher than the steady-state response in $\alpha, \alpha^{\prime}$, MV1, and 
MP1 [two-way ANOVA: $F_{(4,3)}=82.07$; Bonferroni's test: $t_{(3)}=7.87(\alpha), 6.23$ $\left(\alpha^{\prime}\right), 4.07$ (V1), 6.07 (MV1), and 8.19 (MP1), $p<0.01$ ] (Fig. 4), whereas the steady-state tonic activity was significantly above baseline in $\alpha$ and MP1 (Bonferroni's test: $t_{(3)}=5.43$ and 3.03, respectively, $p<0.05)$. Therefore, dopaminergic neurons exhibited primarily phasic responses to cooling, with an additional, smaller tonic response component in $\alpha$ and MP1. These data indicate that dopaminergic responses are biased toward the initial decrease in temperature.

The observation that dopaminergic neurons responded to cooling raised the question of which thermosensory neurons underlie these responses. Thermoreceptors are located in various regions across the body in insects, including the antennae (Davis and Sokolove, 1975; Sayeed and Benzer, 1996; Zars, 2001; Gallio et al., 2011), brain (Hamada et al., 2008), larval terminal organ and multidendritic neurons (Liu et al., 2003), and the tarsi (Kerkut and Taylor, 1957; Reinouts van Haga and Mitchell, 1975). To localize the neuronal circuitry underlying the cold responses in dopaminergic neurons, I performed a set of experimental manipulations and imaged MV1 and MP1 while cooling the fly (Fig. 5). These experiments revealed a significant main effect of treatment (two-way ANOVA: $\left.F_{(4,2)}=25.58, p<0.001\right)$. First, I applied $1 \mu \mathrm{M}$ TTX in the bath solution to silence neuronal activity $(n=13)$. This eliminated the responses to cooling [Bonferroni's test: $t_{(1)}=6.17(\mathrm{MV} 1)$ and $6.78(\mathrm{MP} 1)$ relative to controls, $p<$ $0.001]$. The peak $\Delta F / F$ values in fact dropped below the prestimulation values as a result of a small but consistent downward deflection of the traces [Bonferroni's test: $t_{(1)}=5.00$ (MV1) and 3.20 (MP1) relative to controls, $p<0.01]$. This may reflect a small effect of temperature on the reporter that was unmasked once the cooling responses (that are opposite in sign) were eliminated. These data suggest that the responses are not an intrinsic effect of temperature on either the reporter or dopaminergic neurons and require action potentials (i.e., neuronal activity), presumably in afferent sensory pathways.

To determine which body structure contains the thermosensory neurons that provide input to dopaminergic neurons, I performed several surgical ablations and imaged the cooling responses in MV1 and MP1 (Fig. 5). First, I tested whether the thermoreceptors reside in the antenna (including the arista) by ablating all three antennal segments bilaterally in a set of flies $(n=19)$. The magnitude of the responses was reduced in MV1 significantly (Bonferroni's test: $t_{(1)}=3.17, p<0.05$ ), although
C
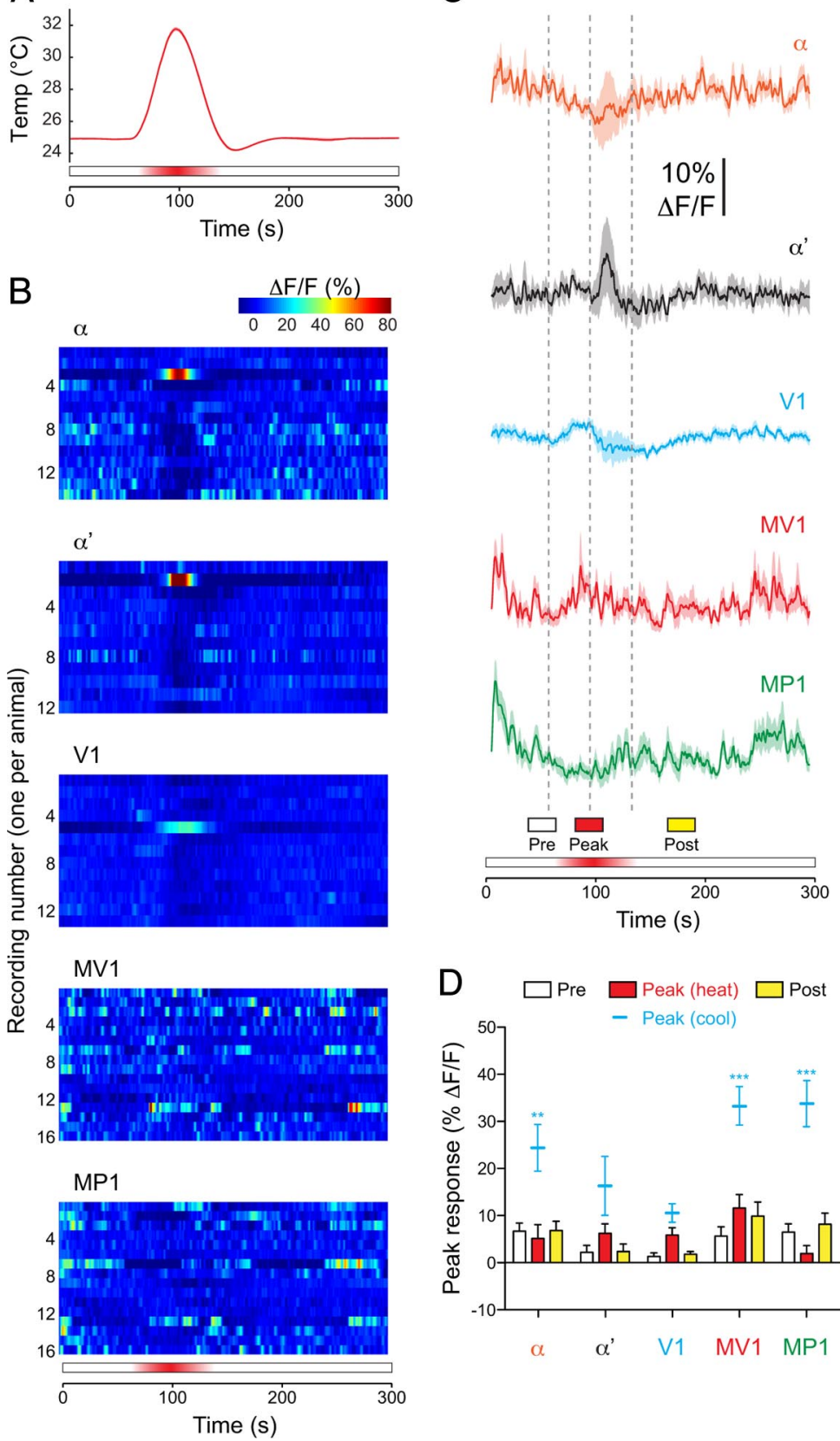

Figure 3. Dopaminergic neurons did not respond to increases in temperature. $\boldsymbol{A}$, Temperature recorded next to the fly's head during brief heating experiments. Mean (dark red) \pm SEM (light red surround) are graphed $(n=30)$. $\boldsymbol{B}$, Heat maps of the responses of individual dopaminergic neurons (1 imaged per fly) to brief heating. $\boldsymbol{C}$, Responses of each subset of dopaminergic neurons to brief heating. Mean (dark lines) \pm SEM (light surrounds) are shown. Vertical dashed gray lines show the beginning, peak, and end of the temperature shift. $D$, Dopaminergic neuron responses to heat across three response windows. For comparison, peak responses to cooling are replotted (mean $\pm \mathrm{SEM}$, without bars) from Figure $1 G .{ }^{* *} p<0.01,{ }^{* * *} p<0.001$ (Bonferroni's test).

there was no significant difference in MP1 (Bonferroni's test: $\left.t_{(1)}=1.97, p>0.05\right)$. This suggests that the antennae may provide some input to MV1, although they cannot be the sole source because the responses were not completely eliminated. Next, I tested the effect of ablating the antennae plus the maxillary palps $(n=12)$, which eliminates all of the canonical olfactory receptor neurons. This ablation significantly reduced the cooling responses in both MV1 and MP1 compared with intact animals (Bonferroni's test: $t_{(1)}=4.41$ and 4.07, respectively, $p<0.001$ ). Compared with the prestimulation responses, there remained a significant peak response in MP1 but not MV1 (Fig. 5B). To 
A
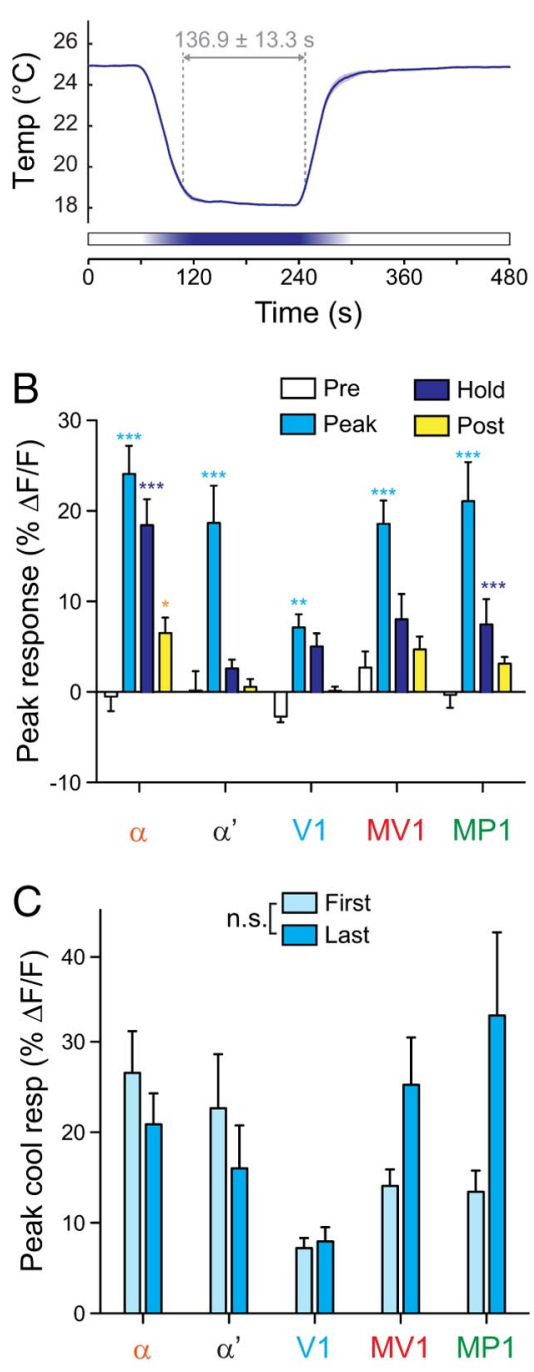

D

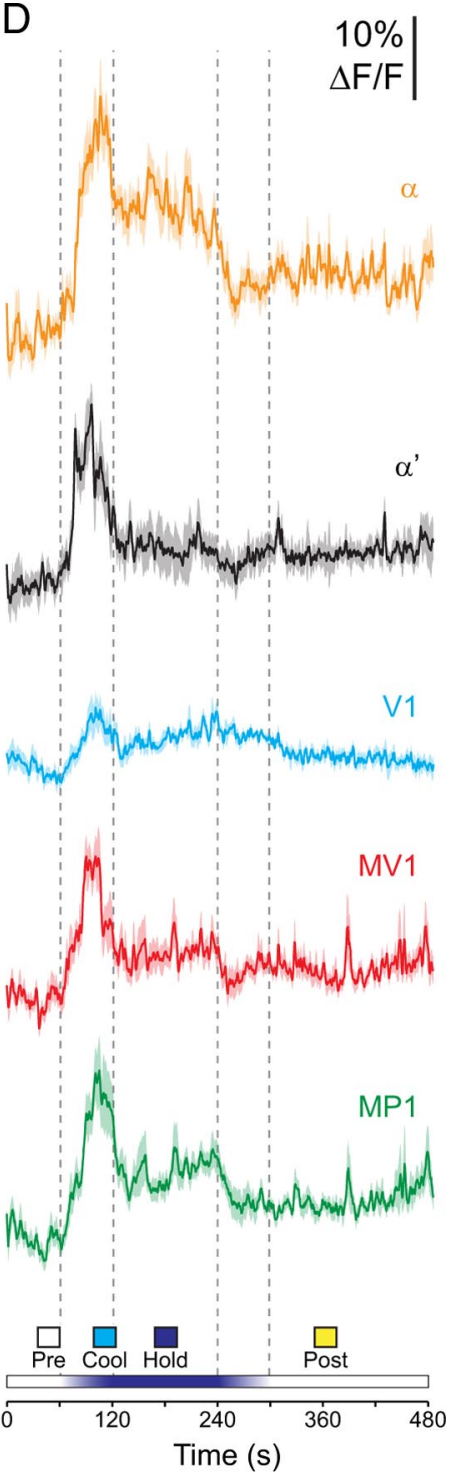

Figure 4. Dopaminergic neurons responded transiently to sustained cooling. $\boldsymbol{A}$, Temperature recorded next to the fly's head during sustained cooling experiments. Mean (dark blue line) \pm SEM (light blue surround) are graphed ( $n=57)$. B. Response magnitudes during four time windows (Pre, Peak, Hold, and Post; see bottom of $\boldsymbol{D}$ ) across each subset of dopaminergic neurons. ${ }^{*} p<0.05,{ }^{* *} p<0.01,{ }^{* * *} p<0.001$ (Bonferroni's test). C, Peak cooling responses graphed based on whether the cooling stimulus was presented first or last. These data are the same set as the peak cooling responses in $\boldsymbol{B}$ (pooled). There was no significant effect of presentation order (two-way ANOVA: $F_{(4,1)}=1.96, p>0.05$ ). $\boldsymbol{D}$, Responses of each subset of dopaminergic neurons to sustained cooling. Mean (dark lines) \pm SEM (light surrounds) are shown. Vertical dashed gray lines show the beginning, peak, and end of the temperature shift.

determine whether thermosensors on the legs (including the tarsi) contribute information to the dopaminergic neurons, the legs were surgically ablated on a separate set of animals $(n=10)$. There was no significant difference in the responses to cooling relative to control animals in either MV1 or MP1 (Bonferroni's test: $t_{(1)}=1.02$ and 0.67 , respectively, $\left.p>0.05\right)$.

The responses of the dopaminergic neurons could be attributable to either the reduction in temperature below a particular threshold (i.e., a fixed threshold below $25^{\circ} \mathrm{C}$ ) or specifically to the change in ambient temperature. To discriminate these possibilities, I tested the responses to temperature ramps in animals starting from $32^{\circ} \mathrm{C}$. The flies were shifted to $32^{\circ} \mathrm{C}$ for $10 \mathrm{~min}$ before imaging, at which point the temperature was ramped down to $25^{\circ} \mathrm{C}$ and back. This paradigm mimicked the $7^{\circ} \mathrm{C}$ temperature drop in the above experiments but from a higher ambient tem- perature. There was a significantly smaller response to this stimulus in both MV1 and MP1 ( $n=12$; Bonferroni's test: $t_{(1)}=$ 3.49 and 4.10, respectively, $p<0.01$ ), although the response was not eliminated in MV1 (Fig. 5). This demonstrates that dopaminergic neurons are capable of responding to changes in temperature that occur from a higher baseline temperature of $32^{\circ} \mathrm{C}$.

The above data demonstrate nearly ubiquitous responses to cooling in the neuropil of the dopaminergic neurons innervating the vertical mushroom body lobes. This raised the question of whether other classes of dopaminergic neurons respond to temperature shifts as well. To address this, I examined the responses of the PAM cluster of dopaminergic neurons innervating the horizontal mushroom body lobes. Ddc-GAL4 promotes expression in dopaminergic and serotonergic neurons (Sitaraman et al., 2008); among these, the cluster of PAM neurons that innervates the horizontal lobes is dopaminergic (Liu et al., 2012). I used this driver to express GCaMP in these neurons and imaged the neuropil of the dopaminergic neurons innervating the horizontal lobes (Fig. 6B). No significant responses were observed to either heating or cooling in these neurons (Fig. 6C,D) (Bonferroni's test: $t_{(1)}=1.66$ and 2.34 , respectively, $p>0.05$ ). Thus, the responses observed in the neurons encompassed by the TH-GAL4 driver were specific to those classes of dopaminergic neurons $\left(\alpha, \alpha^{\prime}, \mathrm{V} 1, \mathrm{MV} 1\right.$, and MP1). Notably, the neuropil of the PAM neurons is adjacent to the MV1 and MP1 neurons, in which consistent, robust responses to cooling were observed.

Imaging the neuropil of the dopaminergic neurons gives a clear indication as to whether there are global responses within spatially separate clusters of neurons but does not provide single-cell resolution in many brain regions. Therefore, to investigate how individual dopaminergic neurons respond to cooling, I imaged the responses of individual somata with the TH-GAL4 driver. This driver allows imaging of PPL1 somata, as well as a few scattered PAM somata (Fig. 6E,F) (Mao and Davis, 2009). Of 21 PAM somata imaged, none exhibited responses to cooling (Fig. $6 G$ ), and there was no significant difference between the prestimulation and peak stimulation $\Delta F / F$ values (Fig. $6 I$ ) (Bonferroni's test: $t_{(1)}=1.13, p>0.05$ ). In contrast, 12 of 22 PPL1 neurons exhibited robust responses exceeding $10 \% \Delta F / F$ (Fig. $6 H$ ), and the peak-stimulation $\Delta F / F$ values were significantly above precooling levels (Fig. $6 I$ ) (Bonferroni's test: $t_{(1)}$ $=6.77, p<0.0001)$. These data suggest that a subset of the PPL1 neurons exhibit a specific sensory response to cooling, with no significant responses observed in either the neuropil or somata of PAM neurons (imaged with either GAL4 driver). 
Flies behaviorally avoid both cold and warm extremes, distributing around $24^{\circ} \mathrm{C}$ when placed on a temperature gradient (Fig. 7) (Sayeed and Benzer, 1996). A previous study documented a change in temperature preference when dopaminergic neurons encompassed by the TH-GAL4 driver were silenced (Bang et al., 2011), but the subset(s) underlying this effect were not identified. To determine whether any subset of dopaminergic neurons is differentially required for temperature-preference behavior, I conducted a series of temperature-preference behavior assays using a temperature gradient. The temporal and regional gene expression targeting (TARGET) system (McGuire et al., 2003) was used to silence subsets of dopaminergic neurons by conditionally expressing the inwardly rectifying $\mathrm{K}^{+}$channel Kir2.1. The channel was targeted to particular subsets of dopaminergic neurons with the following GAL4 drivers: TH-GAL4 (broad dopaminergic driver), C150 (V1, MV1, and MP1), MZ840, NP7135, and NP7198 (V1), C061 (MP1), and NP5272 (M3) (Fig. 7C). GAL4 drivers that express specifically in MV1, MZ604, and NP2755 generated complete lethality when driving Kir2.1 and thus were not examined further. When expressed pan-neuronally with the elav-GAL4 driver, this channel produced lethality as measured $24 \mathrm{~h}$ after induction (switching the flies from 18 to $32^{\circ} \mathrm{C}$ ), confirming the potency of expressing Kir2.1 with TARGET. Flies with no Kir2.1 expression clustered around bins 8 and/or 9 on the temperature gradient, corresponding to temperatures of 23.726. $7^{\circ} \mathrm{C}$ (Fig. $7 D-G$ ).

Silencing dopaminergic neurons using the broad TH-GAL4 driver resulted in a deficit in temperature-preference behavior. The distribution of flies on the temperature gradient was flattened in flies with induced expression of Kir2.1 in dopaminergic neurons (Fig. 7D). The difference was reflected in a loss of cold avoidance $\left(n=10\right.$; two-way ANOVA: $F_{(5,1)}=17.93$ for interaction, $p<0.001$; Bonferroni's test: $t_{(1)}=7.04, p<0.001$ ) (Fig. $7 H)$, whereas heat avoidance was not significantly altered $\left(t_{(1)}=\right.$ 2.56, $p>0.05$ ) (Fig. 7I).

Next, I tested whether subsets of the dopaminergic neurons innervating the mushroom body vertical lobes support temperature-preference behavior. The V1 neuron was silenced with expression of Kir2.1 under control of three independent GAL4 drivers: MZ840, NP7198, and NP7135 (Fig. 7C,G-I). Expression of Kir2.1 in V1 did not affect hot or cold avoidance [Bonferroni's test: $t_{(1)}=0.62$ and 0.04 (MZ840), 0.23 and 0.89 (NP7198), and 0.07 and 1.35 (NP7135) for $\mathrm{AI}_{\text {high }}$ and $\mathrm{AI}_{\text {low }}$, respectively, $p>0.05$ ] (Fig. 7G-I). The C061 driver was used to express Kir2.1 in the MP1 neurons innervating the mushroom body heel. Flies with silenced MP1 neurons also did not exhibit any significant change in heat/cold avoidance [Bonferroni's test: $t_{(1)}=1.72\left(\mathrm{AI}_{\text {high }}\right)$ and $1.47\left(\mathrm{AI}_{\text {low }}\right), p>0.05$ ] (Fig. $\left.7 F, H, I\right)$. C150, which drives expression in V1, MV, and MP, was also tested. This driver produced lethality when flies were incubated at $30^{\circ} \mathrm{C}$ for $\geq 4 \mathrm{~d}$, so I tested the flies with a $3 \mathrm{~d}$ incubation (Kir2.1 expression is effective within $16 \mathrm{~h}$ in this paradigm; Bang et al., 2011). These flies also showed no change in avoidance indices against high and low temperature during Kir2.1 induction [Bonferroni's test: $t_{(1)}=0.97\left(\mathrm{AI}_{\text {high }}\right)$ and $0.64\left(\mathrm{AI}_{\text {low }}\right), p>0.05$ ] (Fig. $7 E, H, I)$. Finally, the NP5272 GAL4 driver was used to inhibit the activity of the M3 neurons innervating a segment of the mushroom body horizontal lobes (Tanaka et al., 2008). Again, these flies showed no deficit in either high or low temperature avoidance [Bonferroni's test: $t_{(1)}=1.30\left(\mathrm{AI}_{\text {high }}\right)$ and $0.41\left(\mathrm{AI}_{\text {low }}\right), p>$ 0.05] (Fig. 7 H,I).

The results of the temperature-preference behavior experiments demonstrate that, although MV1 and MP1 exhibit robust responses to cooling, they are not required for normal temperature-preference behavior (and neither are V1 or M3). This leaves the subset of dopaminergic neurons innervating the $\alpha$ and $\alpha^{\prime}$ tips as the neurons responsible for the cold avoidance effect. Combined with the imaging data, these results suggest that cooling elicits activity across broadly distributed dopaminergic neurons and that a small subset of these neurons is capable of supporting normal temperature-preference behavior. Given that the MV1 and MP1 neurons strongly respond to cooling, it is likely that these neurons function redundantly with the $\alpha, \alpha^{\prime}$, and M3 dopaminergic neurons to encode temperature and guide appropriate behavioral responses.

\section{Discussion}

The present study addresses several fundamental questions regarding the role of dopaminergic neurons innervating the mushroom body. First, do dopaminergic neurons encode stimulus value? Second, to what extent do the parallel arrays of dopaminergic neurons innervating the mushroom body segregate func- 
A

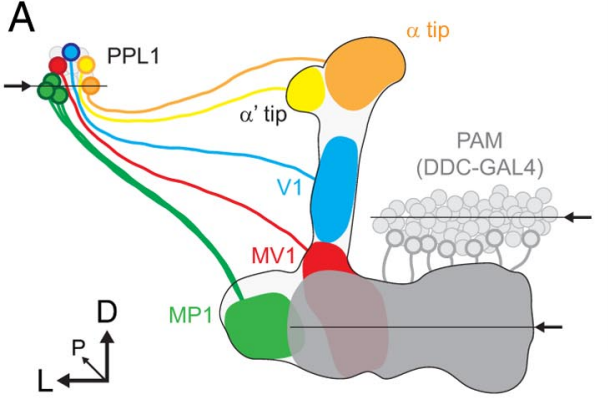

C
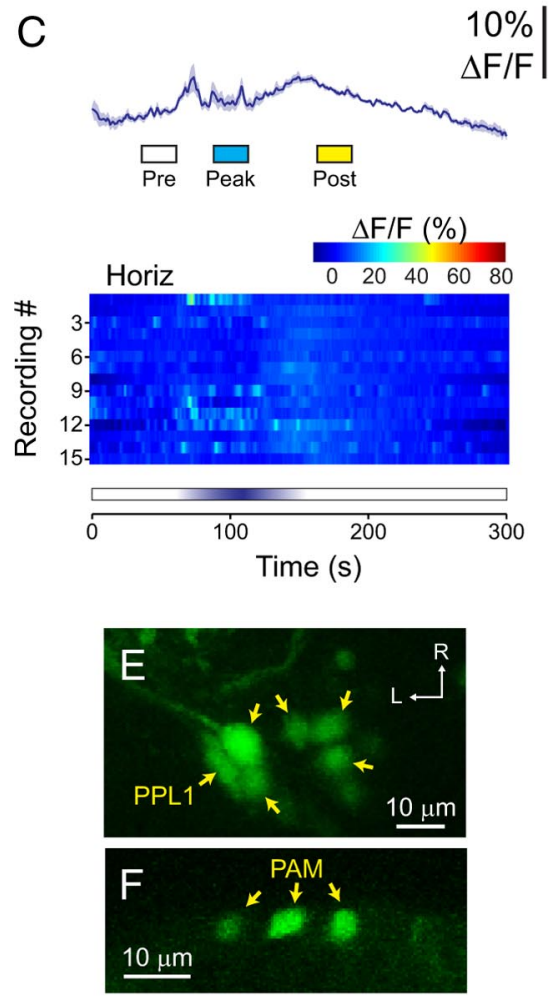

I

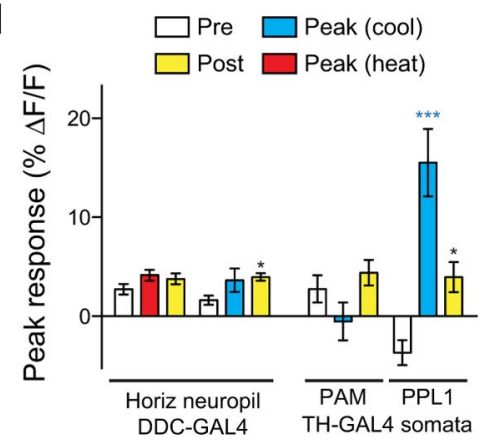

D
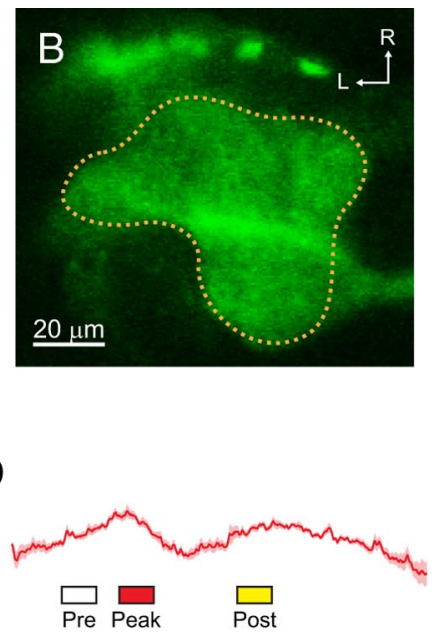

Pre Peak Post

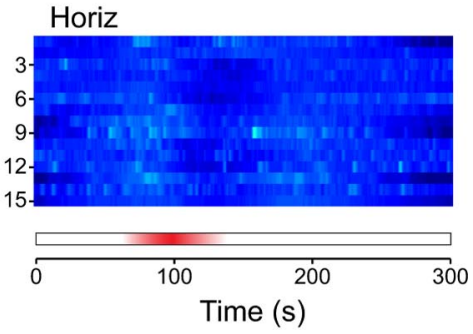

G

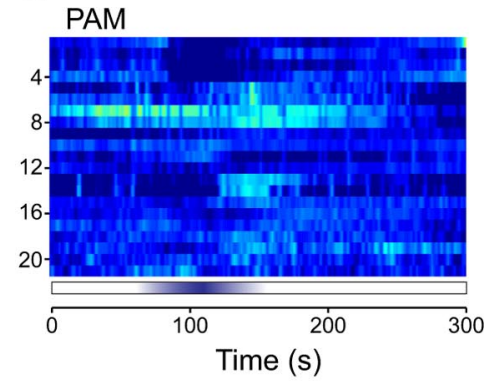

$\mathrm{H}$

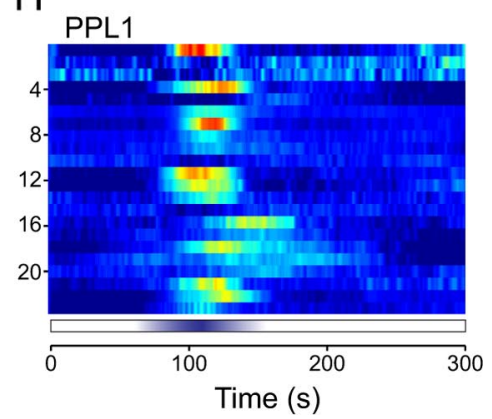

Figure 6. Responses to cooling were specific to a subset of PPL1 dopaminergic neurons. $\boldsymbol{A}$, Illustration of the dopaminergic neurons from the PPL1 and PAM clusters that innervate the mushroom body vertical and horizontal lobes, respectively. The mushroom body lobes are outlined, and each subset of dopaminergic neurons is illustrated in a different color. Arrows and horizontal lines indicate the planes of optical sections for the imaging experiments. $\boldsymbol{B}$, Confocal image of GCaMP expressed in the PAM dopaminergic neurons innervating the horizontal mushroom body lobes, driven by Ddc-GAL4. The dotted line indicates the outline of the PAM neuropil innervating the mushroom body. $C$, Responses of the PAM neuropil to cooling. Mean (dark lines) \pm SEM (light surrounds) are shown at the top, with heat maps at the bottom. $D$, Responses of the PAM neuropil to heating. The layout is the same as $\boldsymbol{C}$. $\boldsymbol{E}$, GCaMP expressed in the somata of PPL1 neurons with the TH-GAL4 driver. L, Left; R, right. F, GCaMP expressed in scattered somata of PAM neurons with the TH-GAL4 driver. G, Heat map showing the responses of individual PAM somata to cooling. $\boldsymbol{H}$, Heat map showing the responses of individual PPL1 somata to cooling. $\boldsymbol{I}$, Peak response magnitudes during three time windows (Pre, Peak, and Post; see bottom of $(\boldsymbol{C}, \boldsymbol{D}$ ) across neuropil of PAM neurons innervating the horizontal mushroom body lobes (left) and the somata of PPL1 and PAM neurons (right). ${ }^{*} p<0.05,{ }^{* * *} p<0.001$ (Bonferroni's test).

tionality in terms of learned versus innate behaviors? Finally, what sensory information contributes to dopaminergic activity? The imaging and behavioral data suggest that multiple subsets of dopaminergic neurons encode a distributed, asymmetric representation of temperature shifts.

In olfactory associative learning, activity in the dopaminergic neurons innervating the mushroom body vertical lobes is both necessary and sufficient to generate aversion to a paired odorant (Riemensperger et al., 2005; Schroll et al., 2006; Claridge-Chang et al., 2009; Aso et al., 2010, 2012). In addition, dopaminergic neurons respond to aversive stimuli that represent the aversive unconditioned stimuli in pavlovian learning (electric shocks) (Riemensperger et al., 2005; Mao and Davis, 2009). These data provide support for the hypothesis that dopamine functions as an aversive reinforcer in the vertical lobes of the Drosophila mushroom body, encoding hedonic value in an inverse manner to the reward-responsive dopaminergic neurons in mammals (Bromberg-Martin et al., 2010). Previous reports have documented responses to odors in dopaminergic neurons of naive flies (Schroll et al., 2006; Mao and Davis, 2009). Odors used in olfactory classical conditioning are often intrinsically aversive over a wide range of concentrations; therefore, this observation does not rule out a hedonic valuecoding model. However, several studies have also uncovered roles of dopaminergic circuits in appetitive forms of learning in flies (Kim et al., 2007; Krashes et al., 2009; Liu et al., 2012). Furthermore, dopamine is dispensable for a non-olfactory form of spatial learning (Sitaraman et al., 2008).

Given that flies avoid temperatures both above and below their optimum $\left(\sim 24^{\circ} \mathrm{C}\right)$, the hedonic value-coding model of dopaminergic function would predict dopaminergic responses to both heating and cooling. These responses should additionally be fast if they are involved in directly modulating behavior. However, dopaminergic neurons responded only to cooling in the present study, contradicting a strict interpretation of the hedonic value-coding model. In addition, asymmetric behavioral responses to temperature shifts have been reported in other studies. In a conditioned place preference assay, heat serves as negative reinforcer, but cooling has a slightly positive reinforcing property (Zars and Zars, 2006). Silencing dopaminergic neurons innervating the vertical lobes affects temperature-preference behavior asym- 
A
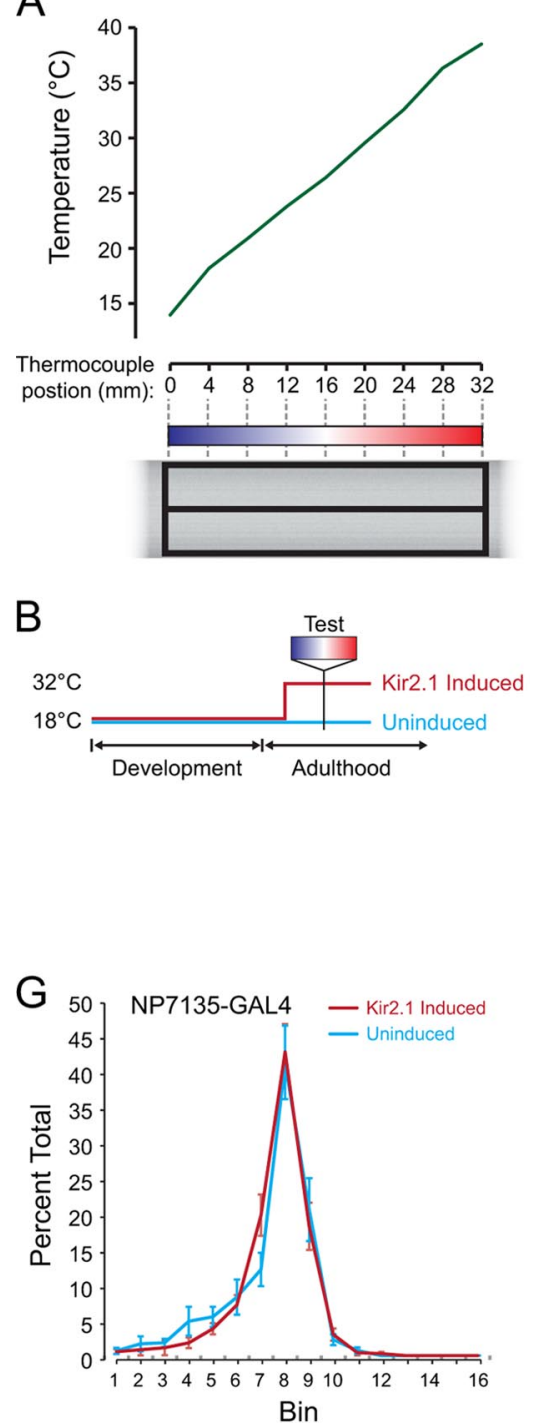

C
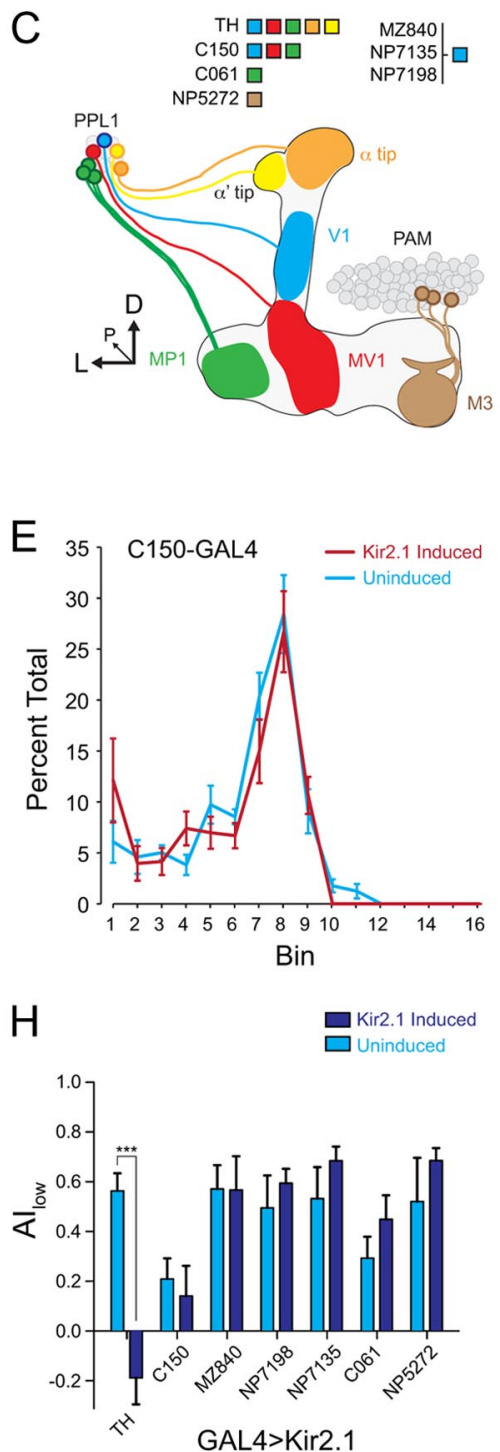
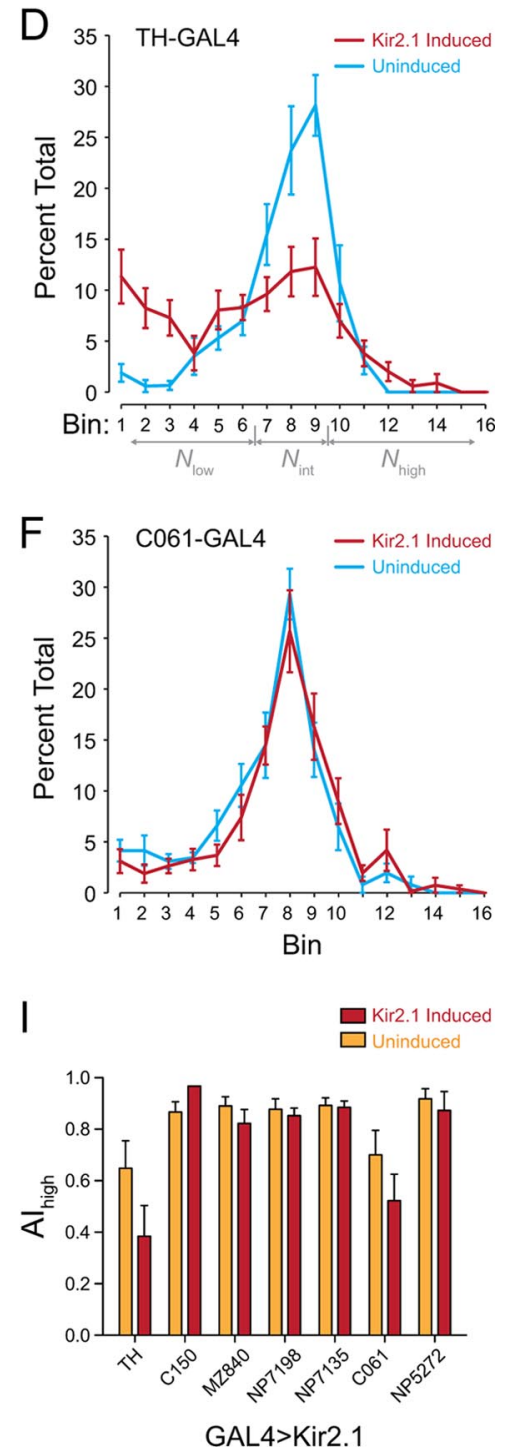

Figure 7. The effects of silencing subsets of dopaminergic neurons on temperature-preference behavior. $\boldsymbol{A}$, The behavioral apparatus and assay conditions. The bottom shows an illustration of the experimental setup, and the mean recorded temperatures across the gradient are graphed at the top $(n=60)$. $\boldsymbol{B}$, Illustration of temperature shifts for TARGET experiments. Flies were raised at $18^{\circ} \mathrm{C}$ and then either kept at $18^{\circ} \mathrm{C}$ or transferred to $30^{\circ} \mathrm{C}$ for $3-4 \mathrm{~d}$ to induce Kir2.1 expression. C, lllustration of the dopaminergic neurons from the PPL1 cluster that innervate the mushroom body lobes. The mushroom body lobes are outlined, and each subset of dopaminergic neurons is illustrated in a different color. The legend indicates the innervation region of each GAL 4 driver. The $\alpha$ and $\alpha^{\prime}$ tips are innervated by dopaminergic neurons that are not yet delineated by individual GAL4 drivers. The V1, MV1, and MP1 neurons innervate the upper stalk, lower stalk/junction, and heel, respectively. D, Dorsal; L, lateral; P, posterior. D-G, Distribution of flies across the temperature gradient, with and without induced Kir2.1 expression under control of different GAL4 drivers. The gray arrows in $\boldsymbol{D}$ indicate the bins that were summed to calculate avoidance indices against high and low temperature. $\boldsymbol{H}$, Avoidance index against low temperatures ( $\mathrm{Al}_{\text {low }}$ ) for all GAL4 lines described in this study. ${ }^{* * *} p<0.001$ (Bonferroni's test). I, Avoidance index against high temperatures ( $\mathrm{Al}_{\text {high }}$ ) for all GAL4 lines described in this study.

metrically, suppressing cold avoidance but leaving heat avoidance essentially intact (Bang et al., 2011; present study). Thus, multiple lines of evidence suggest that dopaminergic circuits innervating the vertical lobes of the mushroom body do not encode a pure punishment signal but rather perform a more complex computation of environmental conditions.

Heating flies to temperatures that produce heat stress $\left(38^{\circ} \mathrm{C}\right.$ for $\left.19 \mathrm{~min}\right)$ impairs memory in a dopamine-dependent manner (Zhang et al., 2008). This suggests that dopaminergic neurons should respond positively to increases in temperature, an effect that was not observed in the present study. These results may be reconciled in at least three ways. First, heat affects flies in multiple ways, for example, modulating locomotor activity and metabolism, as well as triggering circadian entrainment (Zimmerman et al., 1968; Kaushik et al.,
2007; Ueno et al., 2012), which will likely produce effects across many brain regions. In addition, the dopamine effect could be independent of the neurons that innervate the mushroom body, because dopaminergic neurons project to many brain regions (Friggi-Grelin et al., 2003; Mao and Davis, 2009). Finally, the imaging experiments here examined shortterm responses to acute temperature ramps ( $<3 \mathrm{~min})$. Over longer time intervals, dopaminergic neurons may increase their tonic activity at high temperatures. Low-level increases in tonic neuronal activity over relatively long time periods are not easily detectable with calcium indicators in vivo.

Dopaminergic circuits are involved in modulating both innate and learned behaviors. A major aim of this study was to examine how the parallel arrays of dopaminergic neurons innervating the mushroom body encode stimuli associated with these two cate- 

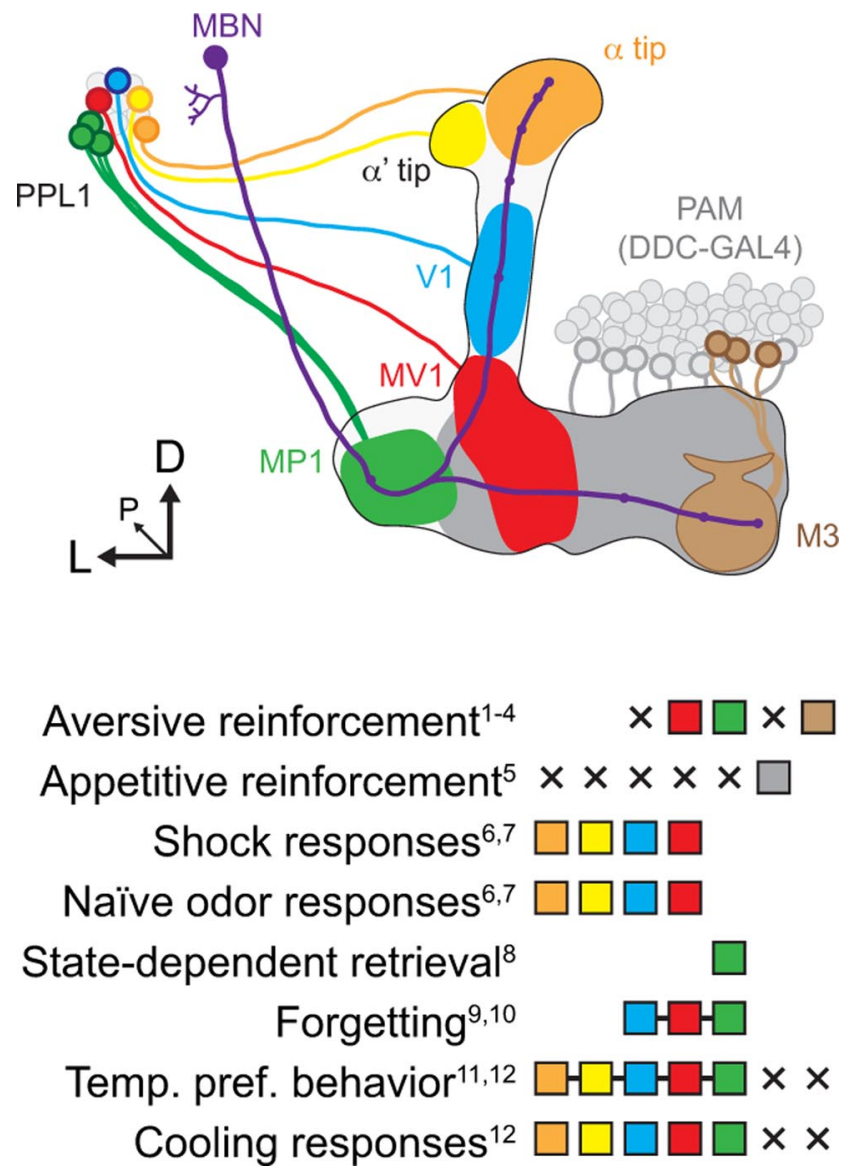

Figure 8. Illustration of the roles of dopaminergic neurons in different behaviors. Evidence for the involvement of a given set of neurons is indicated with a filled square in the legend, whereas evidence against is indicated by an $\times$ symbol. Squares connected with a line indicates evidence for the indivisible set of neurons in a behavior. MBN, Mushroom body neuron. Subscript numbers refer to references: 1, Schroll et al., 2006; 2, Claridge-Chang et al., 2009; 3, Aso et al., 2010; 4, Aso et al., 2012; 5, Liu et al., 2012; 6, Riemensperger et al., 2005; 7, Mao and Davis, 2009; 8, Krashes et al., 2009; 9, Berry et al., 2012; 10, Plaçais et al., 2012; 11, Bang et al., 2011; 12 , present study.

gories of behavior. Learned behaviors could be modulated by dopaminergic circuits distinct from those modulating innate behaviors, or both innate and learned behaviors could be modulated by overlapping dopaminergic circuits. Previous studies have begun to unravel the roles of several subsets of dopaminergic neurons in learning and memory. The MP1 neurons exert motivational control over appetitive memory retrieval (Krashes et al., 2009) and aversive reinforcement (Aso et al., 2010, 2012). The set of dopaminergic neurons defined by the C 150 driver, including the V1, MV1, and MP1 neurons, has been implicated in forgetting (Berry et al., 2012). Thus, there is strong evidence for a role of MP1 neurons in multiple aspects of learned behavior, with V1 and MV1 also possibly playing a role in forgetting.

To compare the role of dopaminergic neurons in encoding stimuli related to an innate behavior (temperature-preference behavior), I examined the encoding of temperature ramps by dopaminergic neurons. Responses to temperature decreases were broadly distributed across multiple subsets of PPL1 dopaminergic neurons. These include neurons involved in motivational control and aversive reinforcement based on hunger state (MP1), forgetting (V1, MV1, and MP1), and neurons with no known role in memory (dopaminergic neurons innervating the $\alpha / \alpha^{\prime}$ tips).
These different subsets include neurons with spontaneous bursting activity (MV1, MP1, and $\alpha$ tip), as well as ones that do not exhibit spontaneous activity (V1 and $\alpha^{\prime}$ tip). Mao and Davis (2009) imaged activity of dopaminergic neurons $\left(\alpha, \alpha^{\prime}, \mathrm{V} 1\right.$, and MV1 regions) in response to both odors and electric shock. Although each stimulus generated regional variations in magnitude, all subsets of dopaminergic neurons responded to odor and shock. Thus, combined with the data from the present study, there is no evidence for segregation of temperature coding from other stimuli involved in associative learning_odor, shock, hunger state, or forgetting signal-across different subsets of PPL1 dopaminergic neurons innervating the mushroom body (Fig. 8). However, there was a difference between the PPL1 cluster and the PAM cluster, because the PAM cluster did not exhibit responses to cooling.

A curious facet of the dopaminergic responses is their unidirectional nature. Where do the sensory signals that feed into the dopaminergic circuits arise?

Thermoreceptors, many of which are differentially cold sensitive, are located in various regions across the body in insects (Kerkut and Taylor, 1957; Davis and Sokolove, 1975; Reinouts van Haga and Mitchell, 1975; Sayeed and Benzer, 1996; Zars, 2001; Liu et al., 2003; Hamada et al., 2008; Gallio et al., 2011). The dopaminergic responses were reduced when both the antennae and maxillary palps were ablated, suggesting that they provide thermosensory input to the dopaminergic neurons.

Dopaminergic neurons responded to cooling with primarily phasic activity, consisting of a burst of activity at the onset of cooling that dropped down to a lower steady-state level at or somewhat above the baseline. Cold-sensitive primary sensory neurons (as well as warm-sensitive ones) respond in a similar phasic-tonic temporal manner (Hensel and Zotterman, 1951; Lacher, 1964; Davis and Sokolove, 1975; Reinouts van Haga and Mitchell, 1975). Therefore, the pattern of dopaminergic neuron activity may follow the response pattern of the sensory neurons. Nonetheless, this response pattern indicates that dopaminergic neuron activity (and consequent release of dopamine onto postsynaptic structures) emphasizes changes in external environmental conditions rather than the static value. Because dopaminergic neurons are involved in learned behaviors, such as associative learning, this response pattern would lend itself well to encoding salient environmental changes. The phasic dopamine release could function to upregulate neuronal plasticity in target structures (e.g., the mushroom body) during periods of environmental change that require acquiring new associative memories or updating previously encoded associations.

\section{References}

Andretic R, van Swinderen B, Greenspan RJ (2005) Dopaminergic modulation of arousal in Drosophila. Curr Biol 15:1165-1175. CrossRef Medline

Aso Y, Siwanowicz I, Bräcker L, Ito K, Kitamoto T, Tanimoto H (2010) Specific dopaminergic neurons for the formation of labile aversive memory. Curr Biol 20:1445-1451. CrossRef Medline

Aso Y, Herb A, Ogueta M, Siwanowicz I, Templier T, Friedrich AB, Ito K, Scholz H, Tanimoto H (2012) Three dopamine pathways induce aversive odor memories with different stability. PLoS Genet 8:e1002768. CrossRef Medline

Bang S, Hyun S, Hong ST, Kang J, Jeong K, Park JJ, Choe J, Chung J (2011) Dopamine signalling in mushroom bodies regulates temperaturepreference behaviour in Drosophila. PLoS Genet 7:e1001346. CrossRef Medline

Berry JA, Cervantes-Sandoval I, Nicholas EP, Davis RL (2012) Dopamine is required for learning and forgetting in Drosophila. Neuron 74:530-542. CrossRef Medline 
Brand AH, Perrimon N (1993) Targeted gene expression as a means of altering cell fates and generating dominant phenotypes. Development 118:401-415. Medline

Bromberg-Martin ES, Matsumoto M, Hikosaka O (2010) Dopamine in motivational control: rewarding, aversive, and alerting. Neuron 68:815-834. CrossRef Medline

Claridge-Chang A, Roorda RD, Vrontou E, Sjulson L, Li H, Hirsh J, Miesenböck G (2009) Writing memories with light-addressable reinforcement circuitry. Cell 139:405-415. CrossRef Medline

Davis EE, Sokolove PG (1975) Temperature responses of antennal receptors of the mosquito, Aedes aegypti. J Comp Physiol A Neuroethol Sens Neural Behav Physiol 96:223-236. CrossRef

Davis RL (2011) Traces of Drosophila memory. Neuron 70:8-19. CrossRef Medline

Doya K (2008) Modulators of decision making. Nat Neurosci 11:410-416. CrossRef Medline

Dubnau J, Chiang AS, Grady L, Barditch J, Gossweiler S, McNeil J, Smith P, Buldoc F, Scott R, Certa U, Broger C, Tully T (2003) The staufen/pumilio pathway is involved in Drosophila long-term memory. Curr Biol 13:286-296. CrossRef Medline

Friggi-Grelin F, Iché M, Birman S (2003) Tissue-specific developmental requirements of Drosophila tyrosine hydroxylase isoforms. Genesis 35:260-269. CrossRef Medline

Gallio M, Ofstad TA, Macpherson LJ, Wang JW, Zuker CS (2011) The coding of temperature in the Drosophila brain. Cell 144:614-624. CrossRef Medline

Gervasi N, Tchénio P, Preat T (2010) PKA dynamics in a Drosophila learning center: coincidence detection by rutabaga adenylyl cyclase and spatial regulation by dunce phosphodiesterase. Neuron 65:516-529. CrossRef Medline

Hamada FN, Rosenzweig M, Kang K, Pulver SR, Ghezzi A, Jegla TJ, Garrity PA (2008) An internal thermal sensor controlling temperature preference in Drosophila. Nature 454:217-220. CrossRef Medline

Hauber W (1998) Involvement of basal ganglia transmitter systems in movement initiation. Prog Neurobiol 56:507-540.

Hensel H, Zotterman Y (1951) The response of the cold receptors to constant cooling. Acta Physiol Scand 22:96-105. CrossRef Medline

Hong ST, Bang S, Hyun S, Kang J, Jeong K, Paik D, Chung J, Kim J (2008) cAMP signalling in mushroom bodies modulates temperature preference behaviour in Drosophila. Nature 454:771-775. CrossRef Medline

Ito K, Suzuki K, Estes P, Ramaswami M, Yamamoto D, Strausfeld NJ (1998) The organization of extrinsic neurons and their implications in the functional roles of the mushroom bodies in Drosophila melanogaster Meigen. Learn Mem 5:52-77. Medline

Kaun KR, Azanchi R, Maung Z, Hirsh J, Heberlein U (2011) A Drosophila model for alcohol reward. Nat Neurosci 14:612-619. CrossRef Medline

Kaushik R, Nawathean P, Busza A, Murad A, Emery P, Rosbash M (2007) PER-TIM interactions with the photoreceptor cryptochrome mediate circadian temperature responses in Drosophila. PLoS Biol 5:e146. CrossRef Medline

Kenny PJ (2011) Reward mechanisms in obesity: new insights and future directions. Neuron 69:664-679. CrossRef Medline

Kerkut GA, Taylor BJ (1957) A temperature receptor in the tarsus of the cockroach, Periplaneta americana. J Exp Biol 34:486-493.

Kim YC, Lee HG, Han KA (2007) D1 dopamine receptor dDA1 is required in the mushroom body neurons for aversive and appetitive learning in Drosophila. J Neurosci 27:7640-7647. CrossRef Medline

Krashes MJ, Keene AC, Leung B, Armstrong JD, Waddell S (2007) Sequential use of mushroom body neuron subsets during Drosophila odor memory processing. Neuron 53:103-115. CrossRef Medline

Krashes MJ, DasGupta S, Vreede A, White B, Armstrong JD, Waddell S (2009) A neural circuit mechanism integrating motivational state with memory expression in Drosophila. Cell 139:416-427. CrossRef Medline

Lacher V (1964) Elektrophysiologische Untersuchungen an einzelnen Rezeptoren für Geruch, Kohlendioxyd, Luftfeuchtigkeit und Tempratur auf den Antennen der Arbeitsbiene und der Drohne (Apis mellifica L.). Z Vergl Physiol 48:587-623. CrossRef

Lebestky T, Chang JS, Dankert H, Zelnik L, Kim YC, Han KA, Wolf FW, Perona P, Anderson DJ (2009) Two different forms of arousal in Drosophila are oppositely regulated by the dopamine D1 receptor ortholog DopR via distinct neural circuits. Neuron 64:522-536. CrossRef Medline

Liu C, Plaçais PY, Yamagata N, Pfeiffer BD, Aso Y, Friedrich AB, Siwanowicz I,
Rubin GM, Preat T, Tanimoto H (2012) A subset of dopamine neurons signals reward for odour memory in Drosophila. Nature 488:512-516. CrossRef Medline

Liu L, Yermolaieva O, Johnson WA, Abboud FM, Welsh MJ (2003) Identification and function of thermosensory neurons in Drosophila larvae. Nat Neurosci 6:267-273. CrossRef Medline

Lüscher C, Malenka RC (2011) Drug-evoked synaptic plasticity in addiction: from molecular changes to circuit remodeling. Neuron 69:650-663. CrossRef Medline

Mao Z, Davis RL (2009) Eight different types of dopaminergic neurons innervate the Drosophila mushroom body neuropil: anatomical and physiological heterogeneity. Front Neural Circuits 3:5. CrossRef Medline

McGuire SE, Le PT, Osborn AJ, Matsumoto K, Davis RL (2003) Spatiotemporal rescue of memory dysfunction in Drosophila. Science 302:1765-1768. CrossRef Medline

Plaçais PY, Trannoy S, Isabel G, Aso Y, Siwanowicz I, Belliart-Guérin G, Vernier P, Birman S, Tanimoto H, Preat T (2012) Slow oscillations in two pairs of dopaminergic neurons gate long-term memory formation in Drosophila. Nat Neurosci 15:592-599. CrossRef Medline

Pramatarova A, Ochalski PG, Lee CH, Howell BW (2006) Mouse disabled 1 regulates the nuclear position of neurons in a Drosophila eye model. Mol Cell Biol 26:1510-1517. CrossRef Medline

Reinouts van Haga HA, Mitchell BK (1975) Temperature receptors on tarsi of the tsetse fly Glossina morsitans West. Nature 255:225-226. CrossRef Medline

Riemensperger T, Völler T, Stock P, Buchner E, Fiala A (2005) Punishment prediction by dopaminergic neurons in Drosophila. Curr Biol 15:1953-1960. CrossRef Medline

Sayeed O, Benzer S (1996) Behavioral genetics of thermosensation and hygrosensation in Drosophila. Proc Natl Acad Sci U S A 93:6079-6084. CrossRef Medline

Schroll C, Riemensperger T, Bucher D, Ehmer J, Völler T, Erbguth K, Gerber B, Hendel T, Nagel G, Buchner E, Fiala A (2006) Light-induced activation of distinct modulatory neurons triggers appetitive or aversive learning in Drosophila larvae. Curr Biol 16:1741-1747. CrossRef Medline

Schwaerzel M, Monastirioti M, Scholz H, Friggi-Grelin F, Birman S, Heisenberg M (2003) Dopamine and octopamine differentiate between aversive and appetitive olfactory memories in Drosophila. J Neurosci 23:10495-10502. Medline

Sitaraman D, Zars M, Laferriere H, Chen YC, Sable-Smith A, Kitamoto T, Rottinghaus GE, Zars T (2008) Serotonin is necessary for place memory in Drosophila. Proc Natl Acad Sci U S A 105:5579-5584. CrossRef Medline

Tanaka NK, Tanimoto H, Ito K (2008) Neuronal assemblies of the Drosophila mushroom body. J Comp Neurol 508:711-755. CrossRef Medline

Tian L, Hires SA, Mao T, Huber D, Chiappe ME, Chalasani SH, Petreanu L, Akerboom J, McKinney SA, Schreiter ER, Bargmann CI, Jayaraman V, Svoboda K, Looger LL (2009) Imaging neural activity in worms, flies and mice with improved GCaMP calcium indicators. Nat Methods 6:875-881. CrossRef Medline

Tomchik SM, Davis RL (2009) Dynamics of learning-related cAMP signaling and stimulus integration in the Drosophila olfactory pathway. Neuron 64:510-521. CrossRef Medline

Ueno T, Tomita J, Kume S, Kume K (2012) Dopamine modulates metabolic rate and temperature sensitivity in Drosophila melanogaster. PLoS One 7:e31513. CrossRef Medline

Waddell S (2010) Dopamine reveals neural circuit mechanisms of fly memory. Trends Neurosci 33:457-464. CrossRef Medline

Wise RA (2004) Dopamine, learning and motivation. Nat Rev Neurosci 5:483-494. CrossRef Medline

Zars M, Zars T (2006) High and low temperatures have unequal reinforcing properties in Drosophila spatial learning. J Comp Physiol A Neuroethol Sens Neural Behav Physiol 192:727-735. CrossRef Medline

Zars T (2001) Two thermosensors in Drosophila have different behavioral functions. J Comp Physiol A Neuroethol Sens Neural Behav Physiol 187:235-242. CrossRef

Zhang K, Guo JZ, Peng Y, Xi W, Guo A (2007) Dopamine-mushroom body circuit regulates saliency-based decision-making in Drosophila. Science 316:1901-1904. CrossRef Medline

Zhang S, Yin Y, Lu H, Guo A (2008) Increased dopaminergic signaling impairs aversive olfactory memory retention in Drosophila. Biochem Biophys Res Commun 370:82-86. CrossRef Medline

Zimmerman WF, Pittendrigh CS, Pavlidis T (1968) Temperature compen- 
sation of the circadian oscillation in Drosophila pseudoobscura and its entrainment by temperature cycles. J Insect Physiol 14:669-684.

CrossRef Medline 